\title{
Educación patrimonial, turismo e inclusión social: acciones para promover el ejercicio de la ciudadanía.
}

\author{
María Inés Travieso Rios* \\ Universidade Federal de Santa Catarina (Brasil) \\ Margarita Nilda Barretto Angeli*** \\ Universidad Federal de Santa Catarina (Brasil)
}

\begin{abstract}
Resumen: El propósito de este artículo es analizar iniciativas educativas desde dos sitios fortificados en América Latina - el conjunto de Fortificaciones al norte de la Isla de Santa Catarina [Brasil] y el Barrio Histórico de Colonia del Sacramento [Uruguay]. Se observó cómo estas acciones socio-educativas, instrumentadas por el turismo, repercuten en sus respectivas comunidades locales promoviendo el ejercicio de la ciudadanía y la inclusión social. Se trata de una investigación de campo y documental realizada para una tesis de maestria defendida en la Universidad Federal de Santa Catarina.
\end{abstract}

Palabras Clave: Patrimonio; Turismo; Educación; Ejercicio de la ciudadanía; Memoria.

\section{Heritage education, tourism and social inclusion: actions for citizenship}

Abstract: The purpose of this article is to analyse the educational initiatives of two fortified sites in Latin America - the Fortifications complex in the North on the island of Santa Catarina [Brazil] and the Historic District of Colonia del Sacramento [Uruguay]. The socio-educational activities., implemented as a result of tourism, have been seen to have an impact on their respective local communities, promoting the exercise of citizenship and social inclusion. This is part of a field and office research into the subject with bibliographical research carried out as part of a master's dissertation defended at the Federal University of Santa Catarina.

Keywords: Heritage; Tourism; Education; Exercise of citizenship; Memory.

\section{Introducción}

Este artículo busca mostrar las distintas formas de utilizar la educación patrimonial y el turismo cultural, en la formación de ciudadanos críticos, apropiados espacial y culturalmente de su territorio, preparados para la valorización y salvaguarda del patrimonio material e inmaterial local. Se trata de dos iniciativas, una de la Escuela del Mar (Escola do Mar) en conjunto con la Universidad Federal de Santa Catarina, en la ciudad de Florianópolis, Brasil, y la otra la llevada a cabo en la Escuela de Oficios Manuel Lobo, en la ciudad de Colonia del Sacramento (Uruguay), que tienen en común un objeto de estudio: las fortalezas.

El patrimonio de ambos lugares está constituido, entre otros, por fortalezas erigidas en el siglo XVIII inclusive con la participación de los mismos actores sociales, como por ejemplo el Brigadier José da Silva Paes (o Pais, según la fuente que se consulte), que en 1737 estuvo a cargo de la defensa de Colonia del Sacramento contra los españoles y luego tomó la Isla de Santa Catarina para Portugal, en ella quedándose como gobernador desde 1739 hasta 1743, y después desde 1746 hasta 1749, y donde construyó el sistema de defensa de la isla.

\footnotetext{
* Universidade Federal de Santa Catarina (Brasil); E-mail: mariainesrios.arq@gmail.com

** Universidade Federal de Santa Catarina (Brasil);E-mail: barretto.margarita@gmail.com
} 


\subsection{Los casos de estudio}

En Florianópolis, se acompañó durante seis meses una iniciativa propuesta por la Escola do Mar en conjunto con la Universidad Federal de Santa Catarina, con alumnos de escuelas públicas de la Isla de Santa Catarina, que consiste en la visita a fortalezas construídas en el siglo XVIII en las islas menores que rodean la isla antes mencionada ${ }^{1}$.

Los paseos turísticos, que surgieron desde los años de 1990, hacia y entre las islas donde se encuentran las fortificaciones dieron infraestructura y un nuevo uso posible para las mismas: el turismo cultural. La iniciativa de educación patrimonial de la Escola do Mar utiliza las mismas rutas marítimas de antaño, dando la posibilidad a los alumnos de poner en valor su identidad cultural y reconocer su patrimonio, ya sea natural o producto de la acción humana. El proyecto propicia el rescate de la relación con el mar $\mathrm{y}$, como resultado, el paisaje costero pasa a integrar el imaginario de los niños no solamente por fotos o relatos de sus antepasados. Así mismo se activan en los adultos memorias de cuando la movilidad era predominantemente por el mar y el uso de la costa era de los pescadores, que fueron siendo expulsados de a poco de su sitio por un turismo de sol y playa que se mantiene como principal actividad económica de la región, habiendo desplazado a la pesca que fuera preponderante hasta la década de 1960 cuando el nucleo fundacional de la ciudad todavía era el centro de convergencia de la Isla de Santa Catarina (Teixeira, 2002:22).

El segundo estudio se refiere al trabajo realizado por la Escuela de Oficios Manuel Lobo, en la ciudad de Colonia del Sacramento, Uruguay. Esta institución actualmente está supervisada por la Intendencia de la ciudad y surgió como resultado de las acciones de organismos internacionales como la UNESCO y la Red de América Latina y España Heritage Watch.

Se analizarán algunas de las experiencias de los estudiantes en el campo del patrimonio, realizadas a partir de 2016, cuando se llevó a cabo el proceso de reciclaje del edificio Frontón Euskaro y de la Plaza de Toros del Complejo Mihanovich, donde la escuela ha estado funcionando desde entonces.

Se buscó comprender los sistemas patrimoniales que surgieron en la ciudad a partir del sello de la UNESCO que propició una relectura del patrimonio histórico y arquitectónico y, al mismo tiempo, al percibir la Escuela como uno de los posibles beneficios de la designación del Barrio Histórico como Patrimonio de la Humanidad, se tomó en cuenta el papel de la institución en su labor de rescate de las técnicas del hacer artesano.

La escuela busca promover la ciudadanía y la inserción en el mercado laboral de sus alumnos como mano de obra calificada para promover la salvaguardia del patrimonio cultural, así como para el restauro. Una vez que el sitio (Barrio Histórico), tiene un valor reconocido por su excepcional integración entre los estilos arquitectónicos portugueses, españoles y postcoloniales, constituye una oportunidad única para la experiencia profesional de los estudiantes.

\section{Primer caso: la Isla de Santa Catarina, Brasil - el mar en un territorio insular.}

La ciudad de Florianópolis, capital del Estado de Santa Catarina, Brasil, tiene la mayor parte de su territorio en la Isla de Santa Catarina que está rodeada de islas de menor tamaño (figura 01). En este paisaje se encuentran tres fortalezas construidas en el siglo XVIII.

El proceso de urbanización de esta región, se fue desarrollando de acuerdo con la tradición portuguesa, a cargo de José da Silva Paes, el primer gobernador de la Provincia de Santa Catarina, responsable por el proyecto del complejo de fortificaciones que protegían el canal norte entre la Isla de Santa Catarina y el continente. Con una ubicación estratégica a medio camino entre Río de Janeiro y la Colonia de Sacramento en el Río de la Plata, dicha isla fue punto de disputa entre las coronas portuguesa y española.

En 1678 se levantó la cruz que dio inicio a la construcción de la capilla de Nossa Senhora do Desterro, siendo esta precisamente la iglesia que habría marcado la fundación del pueblo. La ocupación se dió simultáneamente en el continente y en la Isla. La villa de Desterro se expandió alrededor de la plaza, siguiendo la orientación dada por el mar. En este contexto, las fortificaciones actuaron como redes de conexión entre los núcleos que se formaron a su alrededor.

La villa fue elevada a la condición de sede de la Capitanía de Santa Catarina en 1738 y en 1748 se produjo un crecimiento en la ocupación y colonización de la isla, cuando en menos de 8 años la población aumentó a más de 5 mil habitantes, debido a la llegada de inmigrantes provenientes de las Islas Azores (lo que se conoce como colonización Azoriana). Alrededor de la plaza (que estaba localizada frente al mar) se construyeron la Iglesia Matriz y las primeras edificaciones de carácter oficial como 


\section{Figura 01: [A] Mapa de las fortificaciones de la Isla de Santa Catarina, en 1786 de José Correia Rangel y recorte de las fortalezas investigadas; [B] Mapa actual con las fortificaciones de la Isla de Santa Catarina.}

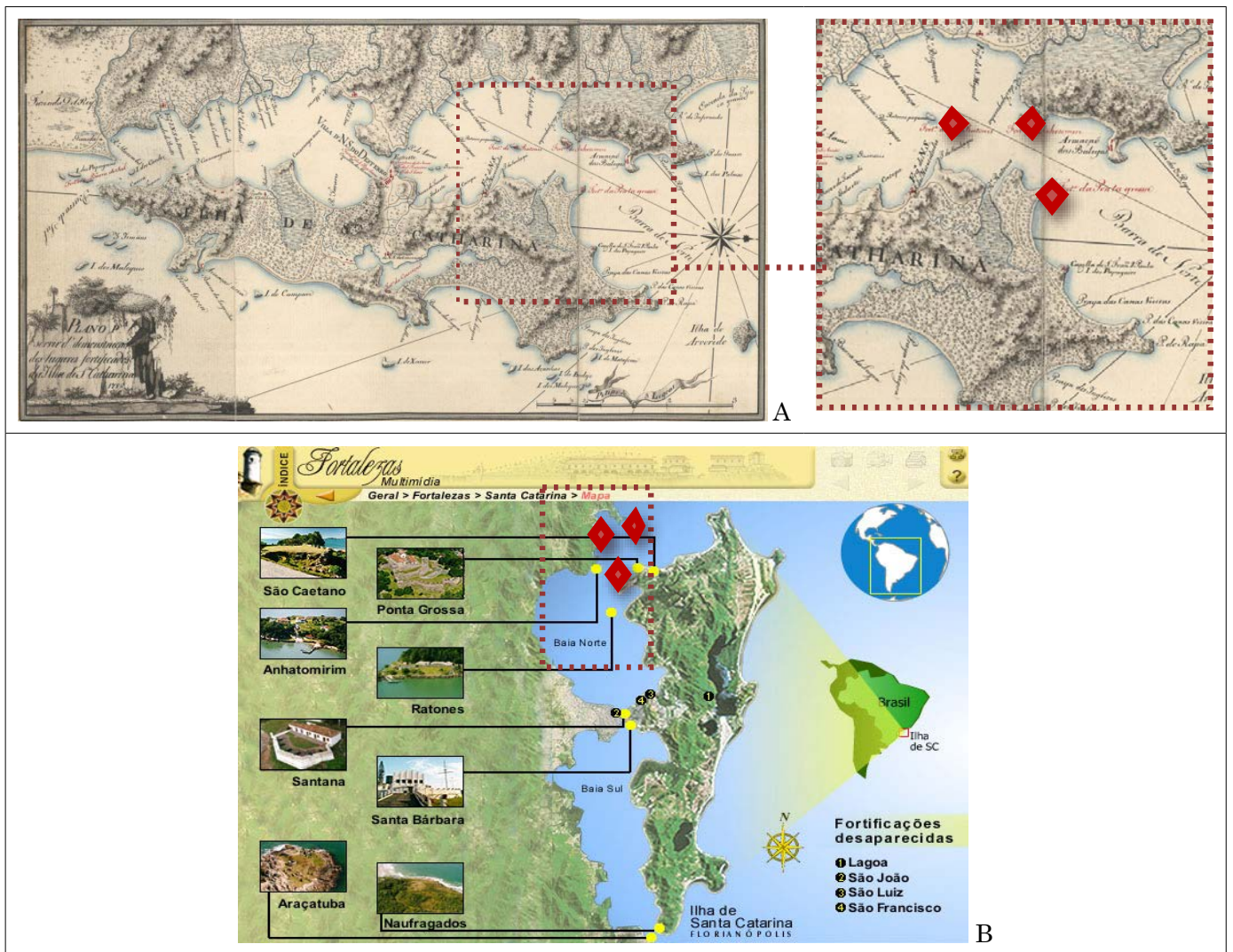

Fuente: Elaboración de las autoras a partir de los mapas - [A] Acervo del Arquivo Histórico Militar de Lisboa, reproducion del libro Tonera\&Oliveira. As defesas da Ilha de Santa Catarina e do Rio Grande de São Pedro em 1786. 2015:92-93; [B] disponible en http://fortalezas.org/?ct=fortaleza\&id_fortaleza=19.

la "Casa de Câmara e Cadeia" (Cámara municipal y cárcel) (1771) y el Palacio del Gobierno (1765) representaciones del poder político-administrativo y religioso. Las fuentes de agua ubicadas en las cercanías, así como las actividades de pesca y agricultura de subsistencia también influenciaron en la determinación fundacional del núcleo urbano. Fue en 1894 que la capital Desterro pasó a llamarse Florianópolis, en homenaje al líder de la Revolución Federalista de 1893, Mariscal Floriano Peixoto y hasta mediados del siglo XX el paisaje que encontrábamos en la Isla era más rural que urbano. En este ambiente, la relación con el mar fue marcante tal como impone un territorio insular, ya sea como forma de subsistencia, de locomoción o de transporte de mercaderías.

\subsection{La relación con el mar}

La estructura de la dinámica urbana, antes determinada por redes de comunicación marítimas y terrestres entre el punto insular central más cercano al continente, y los demás puntos ocupados en la isla se vio fuertemente transformada con la inauguración del Puente Hercílio Luz en 1926. Las redes terrestres fueron fortalecidas y el desplazamiento entre los núcleos costeros pasó a ser más rápido por tierra, tanto en el interior de la isla como en el continente.

Poco a poco el transporte marítimo fue siendo abandonado. El Puente Hercílio Luz, que hoy está presente en el imaginario de los habitantes y visitantes de Florianópolis, como un símbolo de su trayectoria histórica, surge en la década de 1920 marcando la conexión de la parte insular con la parte continental de la ciudad. 
En la década de 1960 con la implementación del Campus de la Universidad Federal de Santa Catarina (en la Isla) y la BR-101 (como ruta de conexión nacional en la parte continental), la ciudad se expande definitivamente hacia el continente reforzando las rutas terrestres. En los años de 1970 (figura 02) surgen los terraplenes de la parte central de la Isla como un elemento de modernización, lo que que acaba separando definitivamente el centro fundacional del mar.

\section{Figura 02: [A] Costa marítima del centro fundacional antes del los terraplenes; [B] Costa con los terraplenes.}
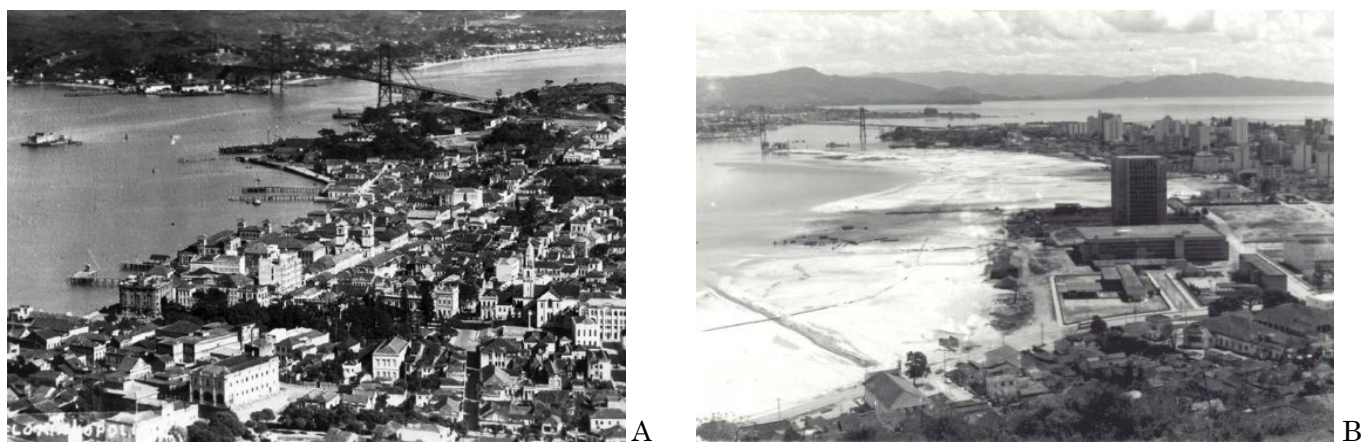

Fuente: Imagens do acervo PET Engenharia Civil - Universidade Federal de Santa Catarina.

El Mercado Público, donde se comercializaban mercaderías directamente de los pescadores artesanales, así como la plaza y los paseos públicos que estaban a la orilla del mar, pierden parte de su identidad paisajística (Teixeira, 2002). Una transformación que con la construcción de los puentes Colombo Salles (1975) y Pedro Ivo (1991) que se suman al Puente Hercilio Luz marcan el cambio de la forma como la ciudad se relaciona con su territorio insular y con el mar. Y, a fines del siglo XX en Florianópolis, se abrirá espacio para una actividad económica, típica de la posmodernidad capitalista, el turismo (Teixeira, 2002: 22).

\subsection{La educación patrimonial y el rescate identitário}

El reconocimiento del sistema de Fortificaciones integrado por las tres fortalezas de la parte norte del canal como patrimonio nacional por parte del "Instituto do Patrimônio Histórico e Artístico Nacional (IPHAN)", comienza en 1938. Después de décadas de abandono, a finales de la década de 1970, el IPHAN coordina los primeros trabajos de arqueología que tienen continuidad en los años de 1980 cuando la fortaleza de Santa Cruz de Anhatomirin pasa a los cuidados de la Universidad Federal de Santa Catarina (UFSC) y la visitación del público se inicia en 1984. Posteriormente, a partir de 1992, este proceso se repite con las fortalezas de Santo Antonio de Ratones y São José da Ponta Grossa. La demarcación de las rutas marítimas entre las islas fortificadas, en el canal norte de la Isla de Santa Catarina, tiene su inicio en la década de 1990, con el "Projeto Fortalezas da Ilha de Santa Catarina - 250 anos na História Brasileira" (Proyecto Fortalezas de la Isla de Santa Catarina - 250 años en la Historia Brasileña) cuando las fortificaciones fueron totalmente restauradas. El mantenimiento y la gestión de los monumentos históricos pasó a ser responsabilidad de la Universidad Federal de Santa Catarina que dió continuidad al proyecto de arqueología y restauración de las edificaciones. En esta década también comenzaron los trayectos de carácter turístico-educativo con la capacitación de guías universitarios (estudiantes de distintas áreas como arquitectura e historia).

En la Fortaleza de São José da Ponta Grossa por estar circunscripta a una pequeña península de la Isla de Santa Catarina, la especulación y consiguiente valorización inmobiliaria del área limítrofe hizo que la comunidad local quedase en contacto directo con una realidad socio-económica muy distinta a la suya. En la década de 1990 surgieron, de forma aislada, algunos proyectos de la UFSC con las comunidades próximas a las fortificaciones. Por ejemplo, se abrieron espacios en las edificaciones patrimoniales para que las rendeiras (tejedoras de encaje) de la comunidad pudieran trabajar y comercializar sus productos. Fueron también ofrecidos cursos adonde las rendeiras enseñaban su 
técnica para los niños de la comunidad, como forma de poner en valor su saber ancestral. Desde entonces se observa el crecimiento turístico cultural en la región, hecho preponderante para el suceso y manutención del proyecto.

Con importante representación económica del turismo en general, la región de la llamada Gran Florianópolis (donde se encuentra nuestro objeto de estudio) ve en el turismo cultural, en particular, la posibilidad de una mayor inversión en la detección de las singularidades patrimoniales de su territorio. En esta perspectiva, en nuestro estudio, percibimos la educación patrimonial como un posible beneficio del proceso de patrimonialización del sítio. Observamos en la iniciativa pionera de la Universidad Federal de Santa Catarina y la Escola do Mar un elemento que viene a nutrir y estimular el rescate del significado histórico cultural del patrimonio territorial por parte de los niños.

\subsection{La iniciativa de la Escola do Mar y de la Universidade Federal de Santa Catarina.}

$\mathrm{Al}$ principio de esta investigación se hizo un relevamiento (Figura 03) de algunos proyectos de educación patrimonial de las escuelas públicas, de distintas regiones del estado, que fueron surgiendo y ampliando su radio de acción en el Estado de Santa Catarina en los últimos años, como consecuencia de la infraestrutura criada por la actividad turística en las fortalezas.

Figura 03: Relevamiento del número de proyectos que visitaron las Fortalezas por las regiones del estado de Santa Catarina (2012-2017)

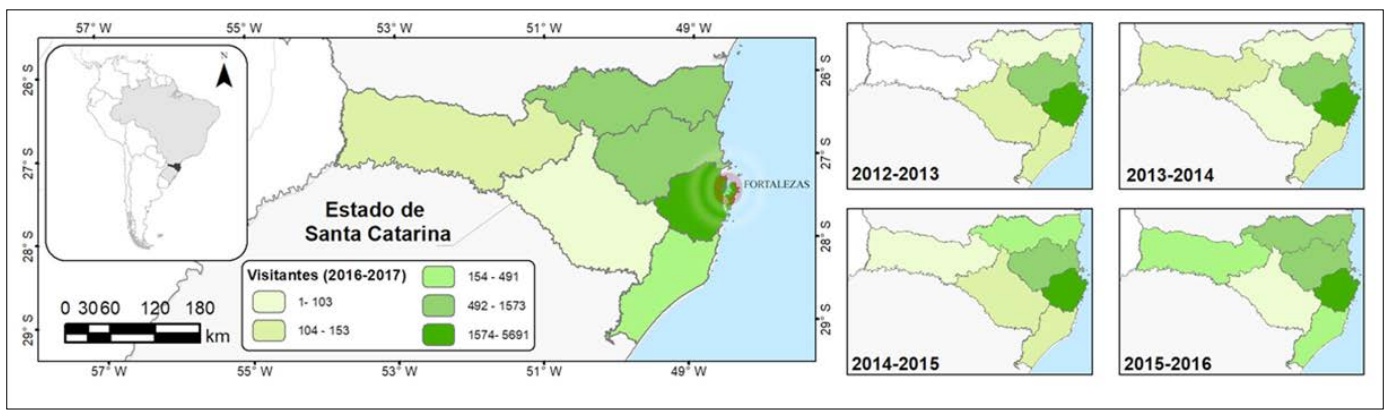

Fuente: Elaboración de las autoras a partir de los datos recogidos en la Coordinación de Fortalezas de la Universidad Federal de Santa Catariana en 2018.

A partir de los datos de visitas a las fortalezas, por parte de estudiantes de instituciones educativas públicas, entre los años de 2012 a 2017, se elaboraron mapas temáticos del estado y con mayor detalle de la región de la Gran Florianópolis para demostrar el alcance territorial de estos proyectos (figura 4).

El proyecto "Fortalezas da Ilha de Santa Catarina" fue reconocido por la comunidad académica y, en 2016, pasó a constituir una dependencia dentro de la Universidade Federal de Santa Catarina. Entre las mejoras que hubo, aquí se destaca la constitución de un grupo dedicado a la educación patrimonial. Esta innovadora visión pedagógica y la posterior asociación con la Escola do Mar de la Administración Municipal de la Ciudad de Florianópolis, hizo posibles las primeras experiencias de paseos por la costa de los alumnos de las escuelas públicas de la ciudad de Florianópolis, después trabajadas en talleres. 
Figura 04: Mapa de visita de las escuelas por origen en la Gran Florianópolis (2012-2017) y análisis de la mobilidad (terrestre y marítima) en el área de estudio - Rutas de turismo

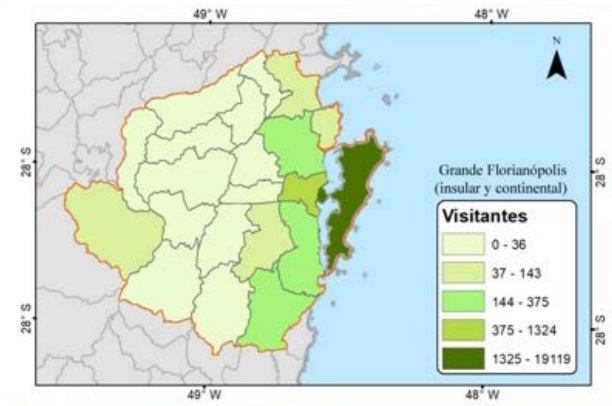

\section{RUTAS PRINCIPALES}
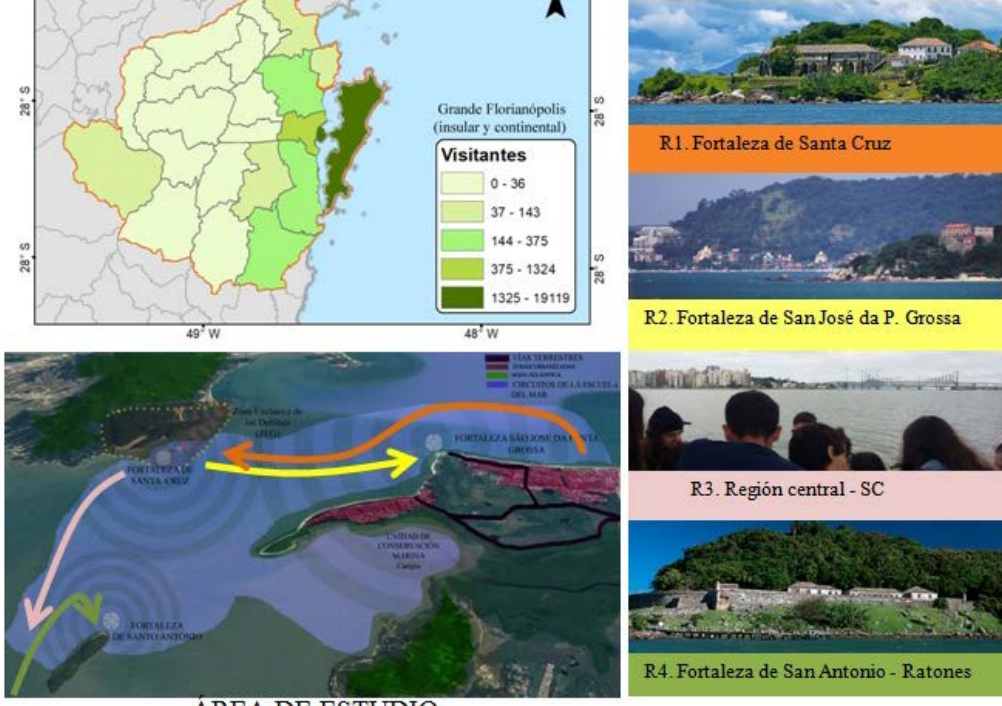

R.2. Fortaleza de San José da P. Grossa

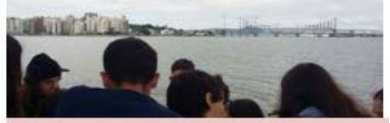

R3. Región central - SC

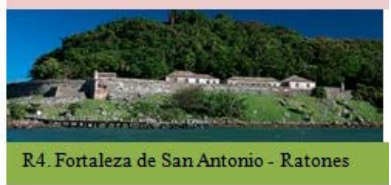

AREA DE ESTUDIO

Fuente: Elaboración de las autoras a partir de los datos recogidos en la Coordinación de Fortalezas de la Universidad Federal de Santa Catariana en 2018.

\subsection{Rescatando el paisaje costero}

Con el objetivo de estimular la percepción del espacio y la valorización del patrimonio local, el gran diferencial de este proyecto queda a cargo de la experiencia pedagógica que comienza en las escuelas, en tierra firme, donde se le explica a los niños, de forma apropiada, la compleja configuración del sitio.

Figura 05: Imágenes de la acción Educativa de la Coord. de las Fortalezas con la Escola do Mar y por último uno de los dibujos de los alumnos de la costa de la Isla al regresar del percurso.
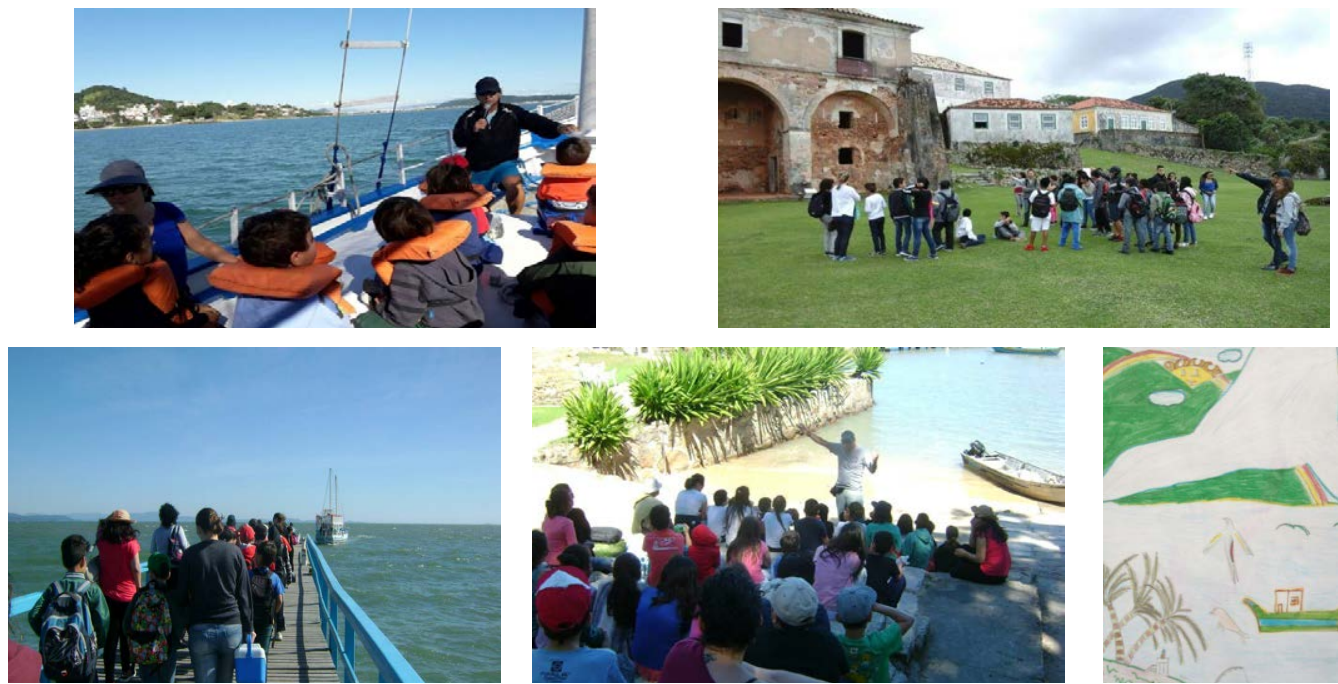

Fuente: Elaboración de las autoras - Escola do Mar - 2018. 
Se propone a los alumnos la reflexión sobre como ellos se relacionan diariamente con el espacio y el mar. Al subir en las embarcaciones de la Escola do Mar, al alejarse de la costa por primera vez observan su comunidad desde otro ángulo. Las imágenes costeras rescatan los relatos de sus antepasados; la experiencia sensorial, las nuevas imágenes ${ }^{2}$ que guardan del paisaje costero, permiten la observación, el reconocimiento, el análisis y la reflexión crítica. Se hace mención a las particularidades del territorio y se pone el énfasis en la coexistencia de la ocupación desordenada de la costa en la Isla de Santa Catarina con los territorios patrimoniales.

$\mathrm{Al}$ analizar los datos observados durante la investigación, buscamos comprender el papel de estas nuevas "imágenes" que se formaron los niños (en su mayoría nietos de pescadores) cuando se dieron cuenta (por primera vez) del espacio donde vivían (una isla) que ahora veían desde el mar. Sentimos el rescate de una memoria costera que anteriormente se había transmitido oralmente y vimos que a través de las "imágenes" aprehendidas en esta nueva experiencia con el sitio, los niños pudieron dialogar con las memorias sus antepasados. Así, el conjunto de recuerdos puede reconfigurar mejor la experiencia sensorial con el nuevo paisaje (Halbwachs, 2013). En el camino de ida y vuelta a las islas de Anhatomirin y Ratones, las fotos y vídeos producidos, así como los dibujos (hecho por los niños mirando la isla desde otra perspectiva) y las redacciones que fueron compartidos en el trabajo posterior a la experiencia, ya en tierra firme, agregaron nuevas imágenes de su territorio a la memoria patrimonial de los alumnos y sus familiares.

\section{Segundo caso: Colonia del Sacramento - Uruguay - un punto estratégico.}

Colonia del Sacramento, fue durante la época colonial y aún es, un punto geopolítico estratégico, ya que se encuentra a $45 \mathrm{~km}$ de Buenos Aires (Capital de la República Argentina) por acceso fluvial y a $180 \mathrm{~km}$ de Montevideo (capital de la República Oriental del Uruguay) por acceso terrestre.

En las orillas uruguayas del Río de la Plata, esta ciudad actualmente con más de veintiseis mil habitantes, tiene un barrio que data del siglo XVII y es en la actualidad llamado Barrio Histórico y fue reconocido como un centro de interés turístico convergente (PGBHCS, 2012: 69).

Figura 06: [A] Mapa de 1640 (de João Teixeira Albernaz) el historiador Marcelo Díaz Buschiazzo llama la atención para la caligrafia posterior de la palabra Colonia que fue fundada en 1680 . Podemos observar las tres ciudades (Montevideo, Colonia del Sacramento y Buenos Aires) como un punto geopolítico estratégico en la Cuenca del Plata. [B] Ruta actual (terrestre y fluvial) por Colonia del Sacramento entre Montevideo y Buenos Aires.
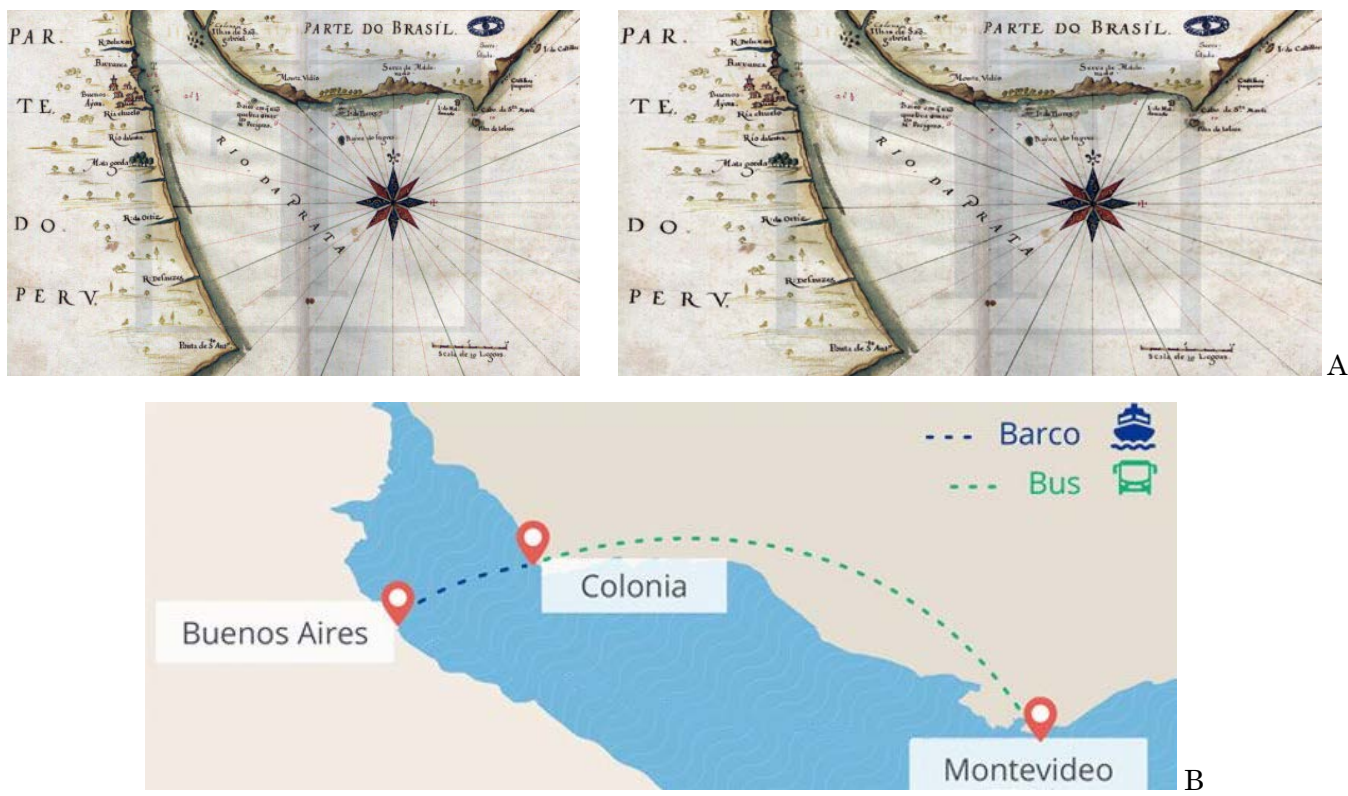

Fuente: [A] Buschiazzo, 2016:46; [B] disponible en www.buquebus.com/rutas. 
La ciudad se conecta por medio de carreteras nacionales (rutas 1 y 21) con los centros turísticos costeros del este y del litoral del país, un hecho que hace que el puerto de Colonia sea reconocido como un actor importante en el turismo nacional e internacional, siendo actualmente la principal puerta de entrada para los turistas En dicho Barrio Histórico se encuentran importantes vestigios de la arquitectura colonial uruguaya.

\section{Figura 07: Localización de la ciudad de Colonia del Sacramento en el Departamento de Colonia y en el Uruguay}

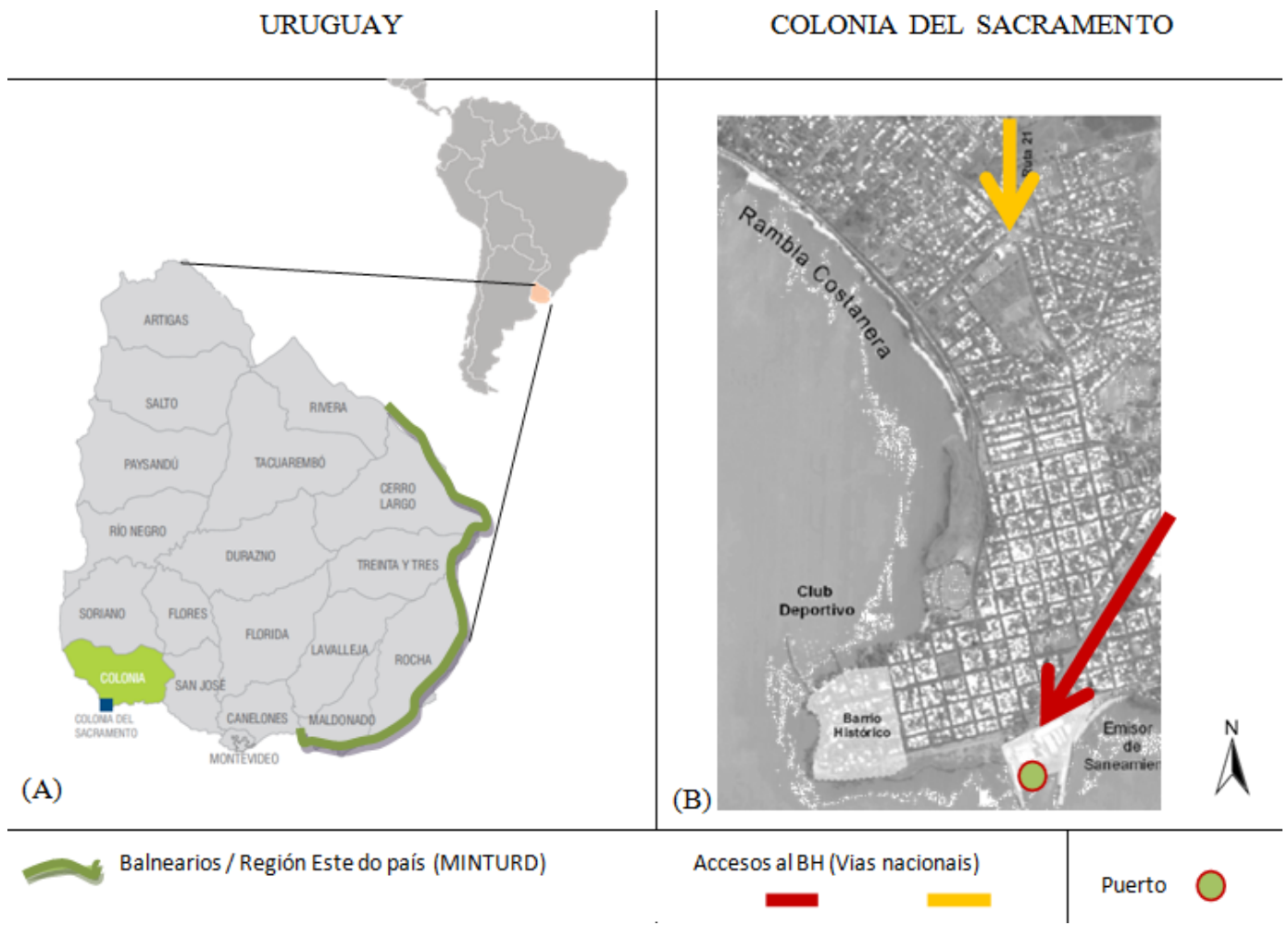

Fuente: A partir del mapa GEOCOLONIA 2009 del Anexo 13 del PGBHCS - archivo digital cedido por la Oficina del Patrimonio de Colonia del Sacramento.

La trama de sus intrincadas calles, el muro perimetral iniciado en la orilla del río, el uso de las barreras naturales del lugar, son característicos de la apropiación de la topografía y el paisaje natural para los propósitos de la corona portuguesa al momento de la fundación. El sitio tiene una fuerte influencia - en el paisaje arquitectónico - de las dos coronas, portuguesa y española, que se alternaron desde la fundación de la ciudad en 1680. Un lugar protegido de los vientos era un puerto seguro en la desembocadura del Río de la Plata, descripto por los historiadores como el principal corredor para llevar los bienes del interior del continente sudamericano desde el siglo XVI hasta el siglo XVIII. Este panorama, junto con la indefinición de la línea Tordesillas ${ }^{3}$, dio origen a la necesidad de demarcar y dominar este territorio, lo que llevó a la fundación, el 20 de enero de 1680, por Portugal, de la "Nova Colonia do Santíssimo Sacramento". 


\section{Figura 08: [A] Plano de la Fortaleza de Colonia del Saramento, Litoral del Uruguay, Rio de la Plata (1680) \\ [B] Aldea de Manuel Lobo, Colonia del Sacrameto em 1680-1704 (1967); [C] Vera Lucitanorum Fortitudines Yghnographica Delignatio (1881)}

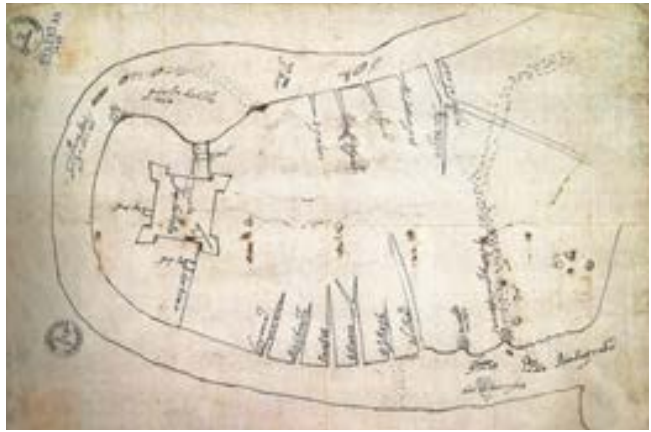

A

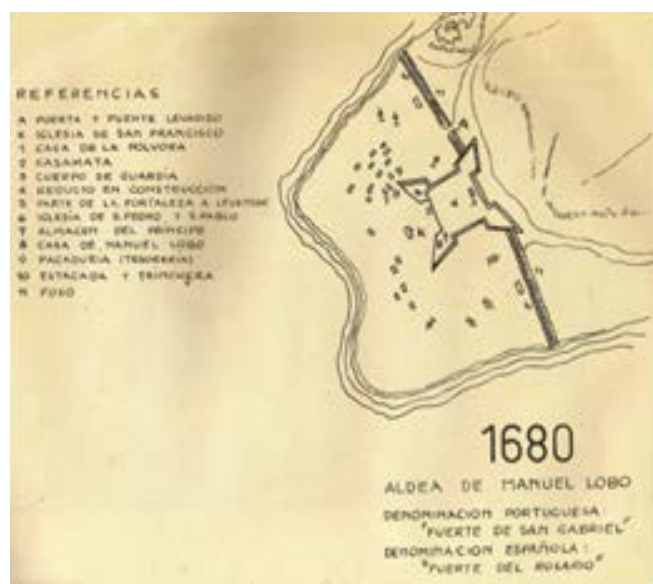

B

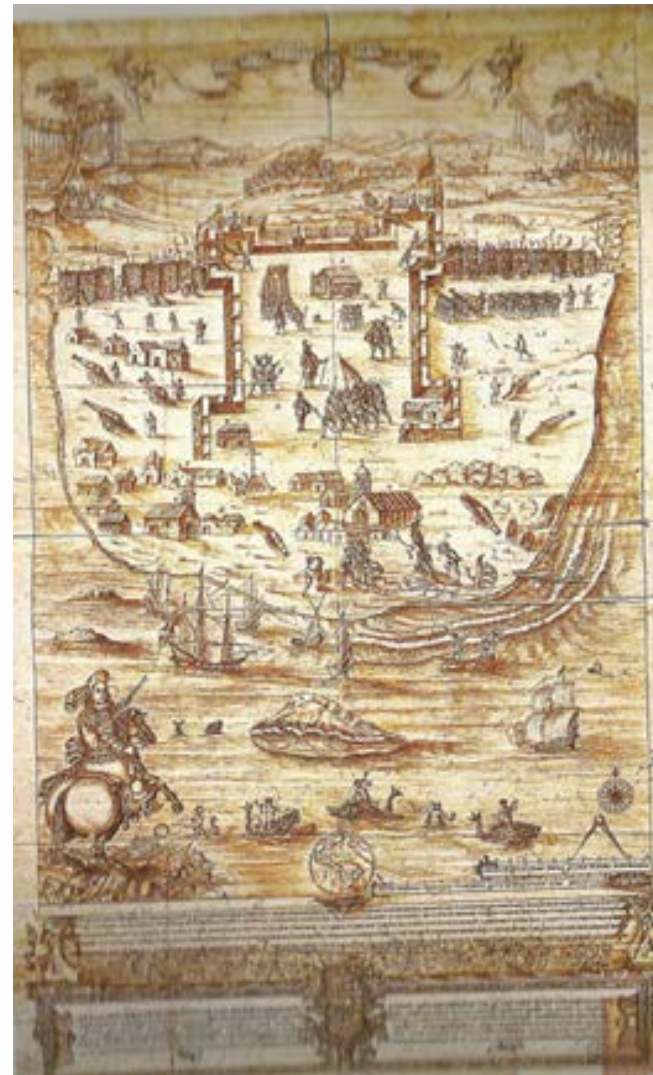

$\mathrm{C}$

Fuente: Del libro Atlas de la Antigua Colonia del Sacramento, 2016. Todos los mapas fueron cedidos por el autor en archivo digital. Orígenes de los mapas:[A] Biblioteca Nacional Rio de Janeiro ; [B] Instituto de Historia, Facultad de Arquitectura, Universidad de la República, montevideo, Uruguay ; [C] Archivo General de las Indias, Sevilla, España.

Manuel Lobo, que era governador de Rio de Janeiro, desembarcó en la isla de San Gabriel y comenzó los cimientos y las primeras construcciones de la Fortaleza del Santísimo Sacramento en la península a orillas del Río de la Plata. Algunos "ranchos" para civiles configuraron la Nueva Colonia Lusitana. Las alternancias de poder en la ciudad continuaron, dejando las marcas de las transformaciones en su territorio, entre ellas en 1762 (España), 1763 (Portugal), 1777 (España), 1807 (Inglaterra). ${ }^{4}$

En las primeras tres décadas del siglo XIX, Uruguay se convirtió en una nación y hubo cambios entre ellos la demolición, en 1859, de la muralla que rodeaba el núcleo fundacional de Colonia del Sacramento. Con ello se produjeron transformaciones significativas en la red urbana de la ciudad con la adopción de la estructura española (en forma de damero). El casco fundacional quedó al margen de esta expansión urbana. A principios del siglo XX los gobernantes y la comunidad consideraban el sitio, conocido como Barrio Sur, como una zona roja (una región con una gran concentración de burdeles) que justificaron una serie de obras para eliminar este aspecto que molestaba a la sociedad local. La ampliación de la Avenida General Flores (hasta hoy avenida principal) es una de las notorias transformaciones de las 
primeras décadas del siglo. Otra transformación es la construcción de un complejo turístico en un barrio situado a $6 \mathrm{~km}$ del centro, llamado Real de San Carlos.

En el mes de mayo de 1909 se firma un acuerdo entre la Intendencia de Colonia y Nicolás Mihanovich para la construcción del Complejo Real de San Carlos. Constaba de Plaza de Toros, Hotel Casino, frontón de pelota vasca, muelle de atraque, tiro al pichón de paloma y usina de energía eléctrica. En junio se iniciaron las obras de la Plaza de Toros. [...] En el mes de enero de 1910 se realiza la primera corrida de toros ${ }^{5}$. (PGBHCS,2012:38).

El núcleo urbano de Real de San Carlos (Figura 09) fue un protagonista de los cambios del siglo XX. La implementación del Hipódromo y el Complejo Turístico de Mihanovich trajeron uso recreativo al Real de San Carlos que, más tarde, redireccionó el crecimiento de la ciudad hacia el oeste (Figura 10).

\section{Figura 09: Embellecimiento del Real de San Carlos - se observa la Plaza de Toros}

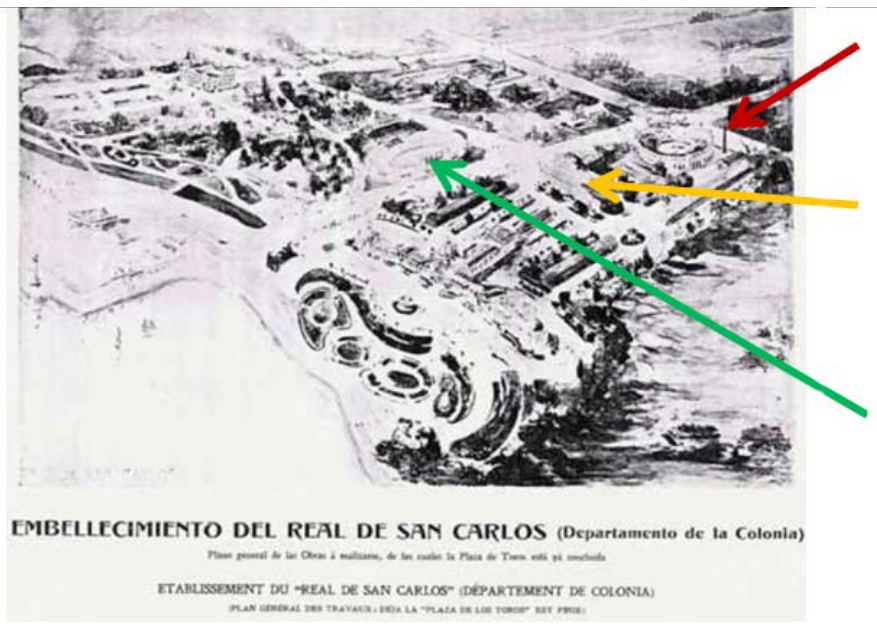

Plaza de Toros

Frontón

Hipódromo Real de San Carlos

Fuente: Elaborado a partir de la Planta PGBHCS

Figura 10: Estudio de la expansión de los límites de la Planta Urbana y Suburbana de la ciudad de Colonia en la primera parte del siglo XX, desde el Casco Fundador hasta y en direccion del Real de San Carlos
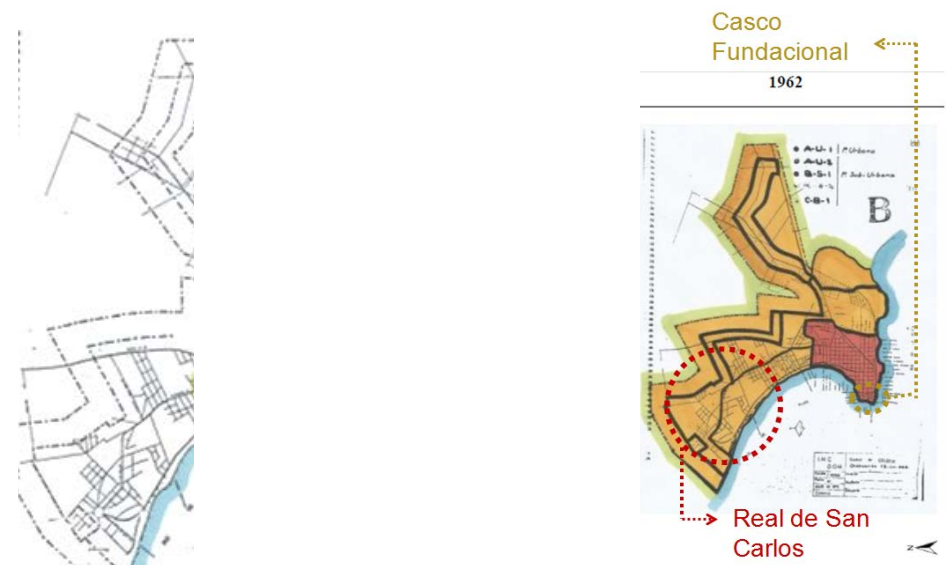

Fuente: A partir del análisis del Plan de los límites urbanos de la ciudad y su legislación correspondiente. Intendencia de Colonia del Sacramento. 


\subsection{Una gestión más allá del Barrio Histórico}

En diciembre de 1995, de la Sesión 19 del Comité del Patrimonio Mundial en Berlín llegó la noticia que se esperaba: el Barrio Histórico de la Antigua Colonia de Sacramento había ingresado en la lista de selección (en ese momento compuesta por poco más de 200 sitios) y fue reconocido como Patrimonio Cultural de la Humanidad. El primer sitio representativo del Uruguay (hasta ese momento) a tener este reconocimiento. El proceso se formalizó en 1992 y fue la culminación de un proyecto que se venia desarrollando desde la segunda mitad de los años ochenta del siglo pasado.

En 2012, se presentó el Plan de Gestión para el Barrio Histórico de Colonia del Sacramento (PGBHCS) como parte de una propuesta para incluir a la comunidad en la gestion del barrio, y para ello se realizaron reuniones públicas y privadas durante el proceso. La intención era construir un Plan "integral e integrador" con la participación de la comunidad local y nacional (PGBHCS, 2012: 18). Para entender el papel de este importante evento en el Barrio Histórico y observar el turismo, y su posible fortalecimiento con la valorización del sitio, debemos comprender los cambios que se produjeron en la forma de percibir el espacio y que se vienen a materializar en el referido plan. Esto, a su vez, se organizó de acuerdo con las directrices de la UNESCO, y para ello se hizo referencia a los documentos correspondientes para la obtención del sello para el Barrio Histórico. A partir de ahí, el sitio patrimonial quedó compuesto de la siguiente manera: el Área Histórica, la Ciudad Histórica [el Barrio y la zona de transición y amortiguación], el paisaje [de la Bahía y las Islas, esta última con Inclusión propuesta en la Lista del Patrimonio Mundial por recomendación de la UNESCO] y la ciudad en su conjunto.

Nunca se deve olvidar que el patrimonio es um barrio, sus casas y calles, un paisaje, un sub-suelo que guarda trazas arqueológicas, que hay autoridades que lo gobiernan y especialistas que lo investigan, pero que lo esencial es su significado para la sociedad y el aprecio que esta siente por esse, "su" patrimonio, herancia de sus padres (PGBHCS,2012:15).

La propuesta para la valorización de la ciudad, como una unidad, aparece para dar la posibilidad al surgimiento de sistemas patrimoniales en otras partes de la ciudad fuera de BH que diversificarían el turismo y que a su vez eliminarían la sobre el barrio. El PGBHCS se configuró como un instrumento calificado para llevar a cabo una gestión integral del desarrollo de BH. Está claro que el documento está preocupado no solo para el presente sino por su visión constante para el futuro, es decir, ver el sitio dentro de la ciudad como un organismo vivo que puede transformarse. Los principales objetivos que guían el documento son la valorización de la cultura y la cohesión social, y la participación. Estos componentes refuerzan las normas y medidas cautelares establecidas.

El eje temático de este programa surge del reconocimiento de los procesos de cambio, en cuanto al establecimiento de los valores y el uso social de la herencia patrimonial. Por ello es prioritario crear alternativas de uso social del bien cultural, a fin de construir espacios de participación democrática en la vida ciudadana, estableciendo responsabilidades colectivas que contribuyan a la conservación del bien, así como a mejorar, directa o indirectamente, la calidad de vida de las personas que conviven con este patrimonio PGBHCS (2012:147).

Con el fin de establecer acciones estratégicas y alcanzar los objetivos propuestos por el Plan de Gestión, se establecieron algunas pautas. Entre ellas y con respecto a las prácticas urbanas, podemos destacar los propósitos de: motivar a la población local para que participe en las acciones de protección, preservación y uso de la Ciudad Histórica; crear y estimular el conocimiento y el uso diario de los espacios públicos en el área central y promover la calidad de vida al estimular las buenas prácticas urbanas (PGNHCS, 2012).

\subsection{Escuela Taller de Artes y Oficios Patrimoniales Manuel Lobo}

La conservación y restauración de monumentos es una disciplina que exige la colaboración de todas las ciencias y técnicas que pueden contribuir al estudio y la salvaguarda del patrimonio monumental (Carta de Venecia, 1964).

La Escuela Taller está vinculada a la Intendencia de la ciudad de Colonia del Sacramento. Cada año, se ofrecen talleres específicos para un período delimitado, se trabaja en doble turno y se enseñan 
tres trabajos distintos: de albañilería, herrería y carpintería. Los cursos se centran en la restauración en el contexto patrimonial y social. A principios de año, se prepara un plan de trabajo, y las diferentes instituciones municipales especifican las necesidades del municipio para el período y de acuerdo con esta demanda establecen las prioridades. Paralelamente, siguiendo el programa propuesto para cada disciplina, el Taller analiza qué intervenciones se pueden llevar a cabo en diferentes lugares. Además de los Talleres, se ofrecen materias complementarias como informática, diseño, seguridad y desarrollo social.

\section{Figura 11: [A,B] Folleto de la Escuel Taller Manuel Lobo; [C] Placa que se encuentra en la Escuela; [D] Registro de los Alumnos en la Escuela}
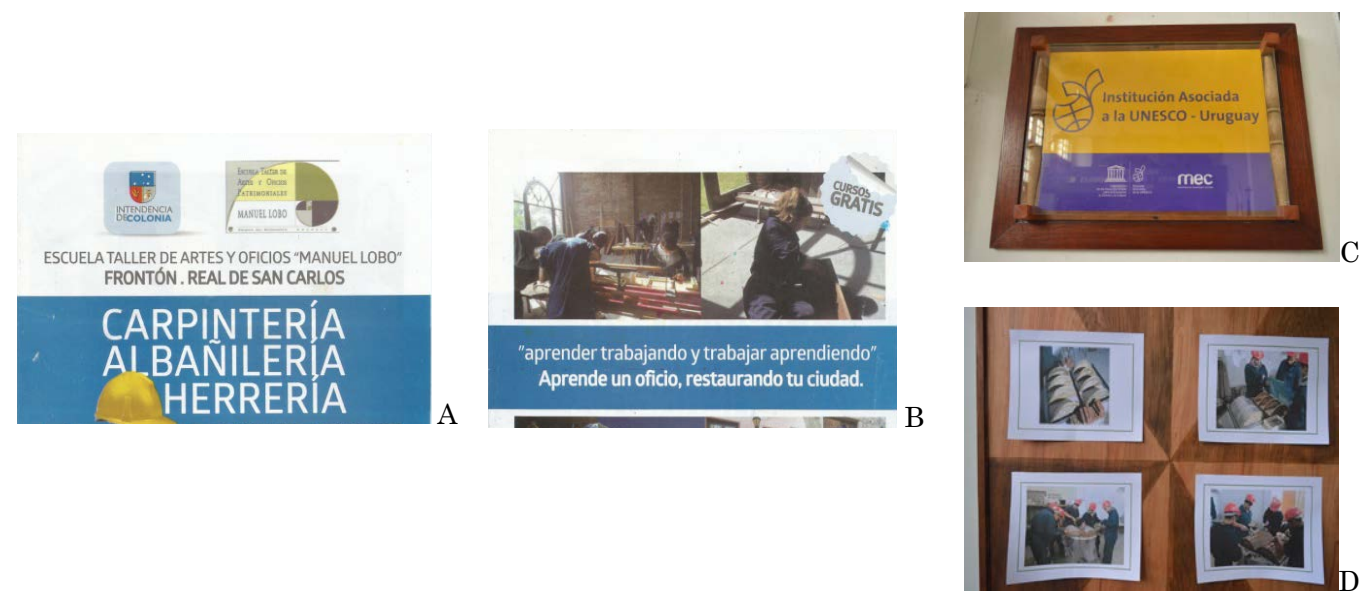

Fuente: $[A, B]$ Digitalizado a partir del original en la Escuela Manuel Lobo; [C,D] fotos de las autoras.

Se realizan intervenciones en el Barrio Histórico y en otros monumentos históricos de la ciudad. Inicialmente, cuando el programa surgió, por uma decisión política, se propuso trabajar con adolescentes de bajos ingresos, de esta manera, según el relato de la profesora Gabriela (2018), la sociedad local llegó a ver el proyecto como una escuela que solo funcionaba para recuperar a estos estudiantes de su precaria situación social. Desde entonces, se han hecho esfuerzos para que los adolescentes asistan a la escuela y desarrollen "hábitos de trabajo" (Gabriela, 2018) o para aprovechar un oficio ya que el $80 \%$ de las clases son prácticas. Con un mínimo de clases teorizantes, el objetivo es que los adolescentes adquieran conocimientos teóricos y que ya trabajen en la práctica. De esta manera, la institución tiene la intención de preparar a los estudiantes para el trabajo y su inserción social en la comunidad local. Desde 2017 y en el año 2018, se modificaron las estructuras del proyecto, con cambios representativos que alcanzaron el nivel de dirección y coordinación del proyecto. De esta manera, se buscó que los adolescentes atendidos no solo sean reconocidos como "excluidos socialmente", sino principalmente que son estudiantes que buscan aprender un oficio técnico calificado. A partir de ese momento, uno de los requisitos para entrar en la escuela es el tercer año de Liceo. Sin embargo, este requisito no es exclusivo, es decir, si el estudiante no está en la serie solicitada por la Escuela Manuel Lobo (que tiene asociaciones con otras instituciones educativas) se propone al estudiante un plan educativo, guiándolo y ayudándolo a alcanzar la meta. El estudiante no recibe el certificado hasta la prueba de su aprobación en la escuela. Con la metodología implementada en los últimos dos años, hubo estudiantes que no alcanzaron el nivel de educación mínimo requerido, pero con las condiciones del programa y con la ayuda de la Escuela, los estudiantes se adaptaron hasta que se logró la educación necesaria. En la escuela hay una preocupación sobre el estudiante y su camino post certificación. Como una forma de garantizar que el estudiante ejerce sus conocimientos en la vida profesional, se han tomado algunas medidas. Se celebran elecciones en las que se reúnen los profesores para elegir a los mejores alumnos. Estos son ahora conocidos como "Pasantes". Anteriormente (antes de esa 
reforma) algunos estudiante se graduaron y los mejores fueron contratados por la Intendencia, pero fueron redirigidos internamente en el cuerpo municipal a otras funciones dentro del sistema. A partir de 2017, la Intendencia contrata al estudiante que se indica por su esfuerzo y compromiso reconocido para convertirse en "Pasante" para transmitir sus conocimientos dentro del propio Taller. Se les paga para trabajar cuatro horas al día. De esta manera, trabajar con el maestro puede mejorar aún más su conocimiento al remediar cualquier brecha en su curso dentro de la escuela. La Escuela Taller cuenta actualmente con tres maestros fijos en los talleres de albañilería, herrería y carpintería. También la institución cuenta con la colaboración de otros profesionales que se ofrecen o están invitados a enseñar las otras clases. En la parte deportiva la escuela cuenta, además, con un entrenador y un recreador del equipo de Futsal de la Escuela que participan anualmente de los Juegos Deportivos Nacionales del Consejo de Educación Secundaria.

En 2018, la Escuela Taller Manuel Lobo contó con la colaboración del arquitecto Jorge Assandri y el historiador Marcelo Diaz Buschiazzo, encargados de transmitir el valor del patrimonio cultural de la ciudad de Colonia a los estudiantes. El arquitecto ya había colaborado con la Escuela en años anteriores, a través de su investigación sobre las inscripciones [RSC] presentes en la vereda del edificio que actualmente alberga la institución.

[...] patrimonio histórico, es una herencia colectiva, no individual, producto de hechos acontecidos, personajes, objetos materiales que han trascendido a través del tiempo, y el espacio social, que llegan a formar parte y esencia de la historia de un lugar, estos objetos culturales son emisarios y nexos entre generaciones humanas y, se forman mediante una construcción social, que es diversa y, responde a las exclusivas maneras de manifestarse la sociedad a la cual pertenece (Cabeza, 2010:03).

El arquitecto Antonio Markonovich fue el autor del proyecto del "Fronton", edificio actual la Escuela. Con 64 metros de largo y 21 de ancho tiene capacidad para 3000 personas. El edifíco fue inaugurado en noviembre de 1910. Fueron realizados dos torneos mundiales, uno en el 1974 y en 1980.

Sobre la base de estas especulaciones, se descubrieron nuevos datos y, junto con el arquitecto Jorge Assandri, los maestros y alumnos de la Escuela desarrollaron un expediente de restauración que se presentó institucionalmente como un proyecto para restaurar la vereda del edifício.

\section{Figura 12: Molde de yeso, de alumínio y baldosa; Registros de los ensayos de la fundición de alumínio y extracción de impurezas, transferencia de modelo a cubeta de yeso y armado de cubetas en arcilla.}
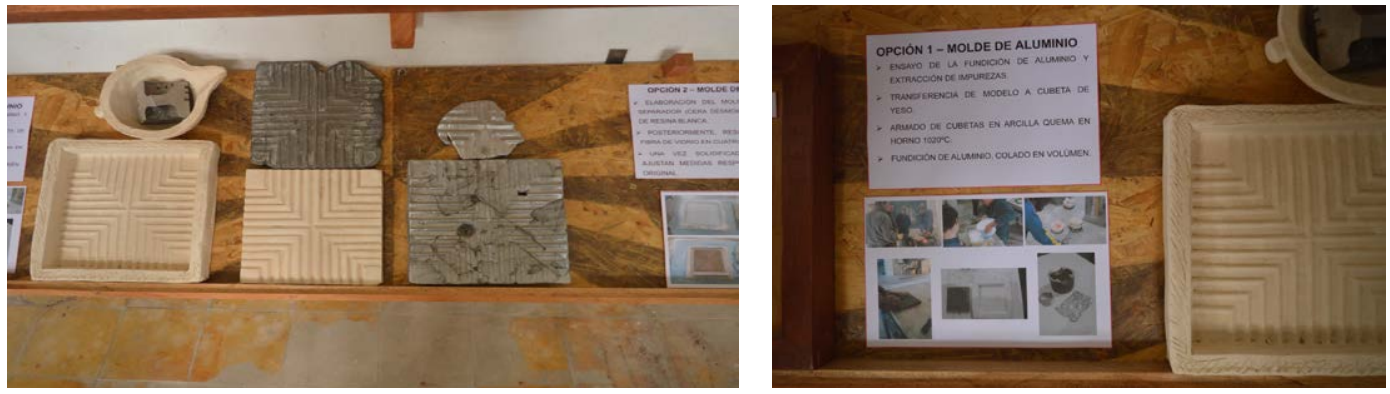

Fuente: Fotos de las autoras en la Escuela, 2018.

Cabe señalar que como las baldosas ya no se fabrican, se buscó una mayor calificación de los profesores para crear subsidios que permitieran la fabricación de nuevas baldosas y para reconstruir las partes faltantes del mosaico descubierto. Después de buscar, sin éxito, los posibles provedores de moldes incluso en otros lugares del país como en Montevideo, se desarrollaron gradualmente todos los moldes. Una investigación exhaustiva con muchas pruebas, permitió reconstituir la unidad del mosaico que forma el acrónimo "RSC" (abreviatura de Real de San Carlos). Esta iniciativa brindó un gran reconocimiento a los estudiantes y a las instituciones. Lo que sirvió de base para una intervención similar en la vereda de la Plaza de Toros de la ciudad a partir de abril de 2018 (Figura13). 


\section{Figura 13: [A] Restitución Grafia del Pavimento RSC y Guardas, Arquitecto Assandri; [B] Foto aérea de los pavimentos exteriores de la Plaza de Toros Real de San Carlos, Colonia del Sacramento; [C] Descubierta y retiro de la capa vegetal sobre la letra $R$, primera jornada 25/ABR/2018}
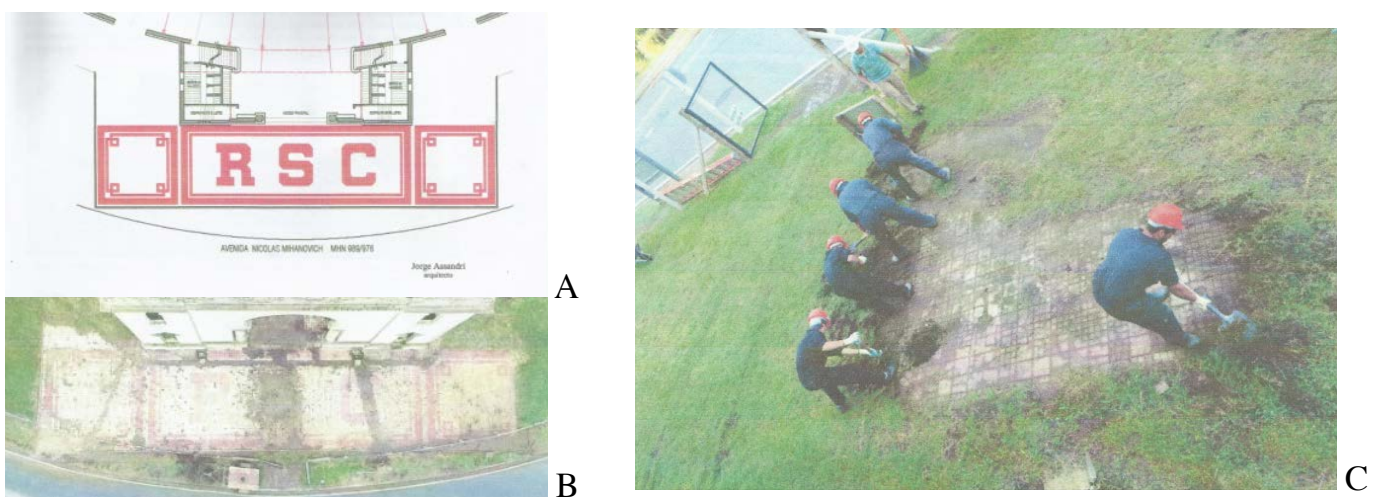

Fuente: Informe preparado por la Escuela Taller Manuel Lobo, copia cedida a las autoras en visita a la institución, 2018.

Después de la higiene del terreno, ya fue posible ver la vereda objeto del proceso de restauración. En este caso, inicialmente se llevó a cabo una limpieza en el lugar del rescate de las piezas y fragmentos que podrían ayudar en el proceso de reconstitución del mosaico. En estos procesos, se debe tener en cuenta que el arquitecto responsable realiza el proyecto de restauración y las especificaciones técnicas necesarias. De este modo establecieron objetivos para que el profesional pudiese transmitir en reuniones y conversaciones temáticas con los jóvenes, sus conocimientos sobre las técnicas necesarias para llevar a cabo la restauración. Si es preciso, debido a las especificidades del proyecto, otros profesionales están invitados a compartir sus teorías y experiencias con los estudiantes. En 2018, otro proyecto que demuestra esta metodología colaborativa es la participación de la Escuela en el "Año Dieste". En el momento en que los estudiantes pudieron asistir a las conferencias con arquitectos y otros profesionales, lo mejor es que los estudiantes adquieran este conocimiento y apropriacion del patrimonio cultural también a nivel nacional.

\section{Consideraciones finales.}

Por los datos aquí presentados podemos considerar la importancia de prestar mayor atención a iniciativas ya estructuradas como la asociación entre la Escuela del Mar y la Universidad Federal de Santa Catarina ${ }^{6}$, con la elaboración de lineamientos que puedan estimular estas acciones y que también lo hagan dentro de la gestión sostenible del sitio patrimonial.

En el caso de Florianópolis, el análisis de la relación entre el observador y el objeto observado fue fundamental. Los resultados obtenidos demuestran que la experiencia de salir del territorio y verlo de otro ángulo se traduce en una mayor apropiación paisajística por parte de los estudiantes, de su territorio (la isla). La importancia de las actividades que registran y materializan las nuevas "imágenes" y las distintas percepciones espaciales de los alumnos ponen en valor su identidad cultural. La experiencia, al salir de la isla por el mar reconstruye un imaginario colectivo, descubren nuevos aspectos patrimoniales del paisaje llamado turístico como una forma de comprender mejor su territorio.

En Colonia del Sacramento el arquitecto Fernando Capurro en 1927 ya describía el Casco Fundacional de la ciudad (hoy Barrio Histórico) como un importante patrimonio nacional del Uruguay. Fue con las acciones de valorización del Comité Ejecutivo Honorario en la década de 1960 y el trabajo del arquitecto M.A. Odriozola, entre otros, que, en un contexto nacional en el que el país necesitaba diversificar sus actividades económicas, el turismo fue visto como una oportunidad. En la ciudad de Colonia, su mayor patrimonio sería visto como un valioso producto turístico, que podría reorientar la economía local. 
Finalmente, el sello de la UNESCO en1995 llevó a un Plan de Gestión (2012). El documento reconoce al turismo como un agente fuerte en el sitio. En una sociedad globalizada, la presencia del turismo en un sitio de la UNESCO es algo previsible, y se han hecho esfuerzos para valorar y medianamente proteger lo que es único en este importante patrimonio local y nacional.

El desarrollo turístico responsable es una oportunidad real para el patrimonio territorial, al ofrecer caminos para conciliar la conservación con las demandas y necesidades sociales, siempre que seamos capaces de trabajar en clave de sistema patrimonial territorial. La lectura del patrimonio territorial como fuente de riqueza abre nuevas vías de acción y el patrimonio, lejos de bloquear el desarrollo económico y social, tiene que convertirse en la lucha contra la pobreza (Troitiño Vinuesa \& Troitiño Torralba, 2018:233).

Hoy, veinticuatro años después del sello, podemos ver en la programación visual de los tótems que señalan las rutas culturales a través de la ciudad de Colonia, la formación de lo que Troitiño Vinuesa ${ }^{7}$ denomina de "sistemas patrimoniales". En otras palabras, desde el núcleo y los bordes protegidos por la distinción de la UNESCO, puede ocurrir un proceso de valorización de áreas y monumentos periféricos, que en algún momento llega a coincidir con la trayectoria histórica y/o cultural del sitio. En este contexto percibimos el complejo del Real de San Carlos como uno de los sistemas patrimoniales que surgieron del Barrio Histórico de Colonia do Sacramento. El papel de la educación patrimonial, - en este caso en la Oficina Taller de Oficios Manuel Lobo - es componer, a través de sus acciones, un posible ciclo de sostenibilidad (Figura 14).

\section{Figura 14: Modelo Explicativo}

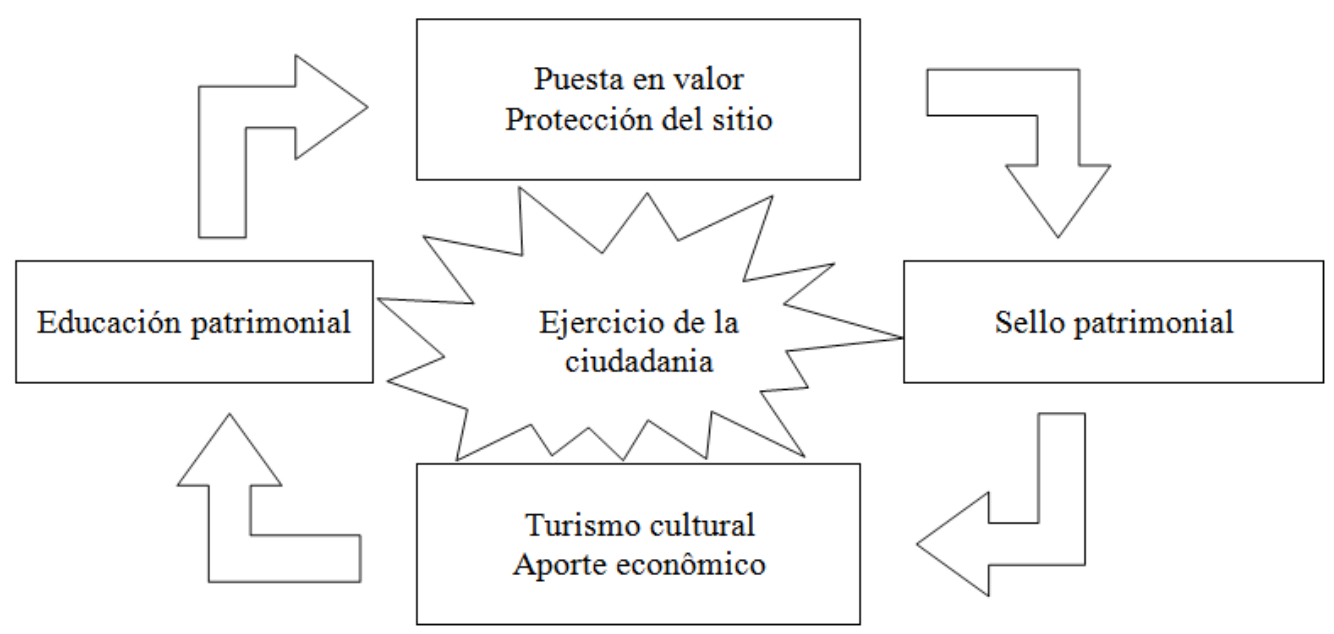

Fuente: Elaboración de las autoras.

En los dos casos investigados, las acciones de educación patrimonial surgen del sello patrimonial (independientemente del grado nacional o mundial) que califica el sitio convirtiéndolo en un producto turístico. De esta manera, el turismo cultural aparece no solo como un aporte económico, sino en estos casos como un actor importante en el desarrollo sociocultural de las comunidades estudiadas. Choay (2011:36) hace referencia a la clasificación por parte de la UNESCO del patrimonio mundial y la responsabilidad que el mismo tiene en la mercantilización patrimonial. En este aspecto observamos también la necesidad de abordar la educación patrimonial como importante herramienta para una gestión consciente del patrimonio natural y cultural de un sitio protegido. Considerando el patrimonio, sea natural o cultural, para el desarrollo local (De Varine, 2013), la puesta en valor de las singularidades paisajísticas del espacio coinciden con una visión más crítica de las trasformaciones culturales y territoriales que se esperan de la relación entre turismo y patrimonio cultural. El turismo como agente económico es importante en 
los dos casos investigados y, asociada a esta actividad, la educación patrimonial surge como una accion para el ejercicio de la ciudadaní una posibilidad de apropiación, identificación y comprometimiento con el patrimonio sea el material o inmaterial.

\section{Bibliografía}

Abreu, M. A. A. 1998. Sobre a memória das cidades. Revista da Faculdade de Letras, Porto, I série. (Geografia, v. XIV).

Argan, G. C. 1993. História da arte como história da cidade. São Paulo: Martins Fontes.

Augé, M. 1994. Não-Lugares: Introdução a uma antropologia da supermodernidade. SP: Papirus.

Barretto, M.; Gislon, M. 2013. O flâneur revisitado: processos de revitalização urbana e caminhabilidade. Revista Hospitalidade. São Paulo, v. X, n. 1, p. 54 - 77, jun.

Barretto, M. 2007. Turismo y cultura. Relaciones, contradicciones y expectativas. Revista Pasos. Tenerife: Asociación Canaria de Antropología.

Barretto, M. 2000. Turismo e Legado Cultural. Campinas: Papirus.

Brandão, R. P. 2017. A Demarcação da Raia Divisória do Tratado de Tordesilhas e a Devolução de Sacramento pelo Tratado Provisional de 1681: complexidades cartográficas e geopolíticas. Anais do XXIX Simpósio Nacional de História. Brasília. Disponible en: http://www.snh2017.anpuh.org/site/ anais (Accedido en: 17/10/2019).

Buschiazzo, M. D. 2016. Atlas de La Antigua Colonia del Sacramento. Colonia del Sacramento: Tradinco.

Buschiazzo, M. D. 2018. Entrevista [01 jul. 2018]. Colonia del Sacramento - Uruguay. 1 archivo .mp3 (01:14:22). Entrevista para la pesquisa de Mestrado.

Cabeza, M. 2010. Criterios y Conceptos sobre patrimonio cultural en el Siglo XXI. UBP Serie Materiales de Enseñanza. Disponible en: https://cicopperu.files.wordpress.com/2019/05/criterios-conceptos-patrimonio-en-siglo-xxi.pdf (Accedido en: 15/03/2018).

Canclini, N. G. 2003. A globalização imaginada. São Paulo: Iluminuras.

Capurro, F. 1928. La Colonia del Sacramento. Montevideo: Sociedad 'Amigos de la Arqueología'.

Cauquelin, A. 2007. A invenção da paisagem. São Paulo. Martins Fonte.

Certeau, M. de. 1994. A Invenção do Cotidiano: 1. Artes de fazer. Tradução de Ephraim Ferreira Alves. Petrópolis, RJ: Vozes.

Charbonnier, F. T. 2012. El adiós al Sur. La creación del Barrio Histórico de Colonia como atractivo turístico in El turismo bajo la lupa académica. Montevideo: Ediciones Universitarias UdeLAR.

Choay, F. 2011. O Patrimônio em questão: antologia para um combate. Belo Horizonte: Fino Traço.

Choay, F. 2001. A Alegoria do Patrimônio. São Paulo: Estação Liberdade. UNESP.

De Varine, H. 2013. As raízes do futuro. O patrimônio a serviço do desenvolvimento local. Porto Alegre: Medianiz.

Falero, A.; Campodónico, R. (comps.) 2014. El turismo bajo la lupa académica. Montevideo: Ediciones Universitárias.

Fusco, N. 1997. Historia de la Arqueología Histórica en el Uruguay-Análisis y Perspectivas. In: Approaches to the Historical Archaeology of Mexico, Central \& South America. Los Angeles: The Institute of Archaeology - University of California.

Fusco, N. 2018. Entrevista [01 jul. 2018]. Colonia del Sacramento - Uruguay. 1 archivo .mp3 (02:37:22). Entrevista para la pesquisa de Mestrado.

Gagnebin, J-M. 2012. Apagar os rastros, recolher os restos. In: Walter Benjamin: rastro, aura e história. Belo Horizonte: UFMG.

Gehl, J. 2013. Cidade para pessoas. 2. Ed. São Paulo: Perspectiva.

Guillot, M. 2004. De Colonia del Sacramento a Colonia-Apuntes del Arq.Miguel Ángel Odriozola Odriozola. Colonia del Sacramento: Santander.

Guillot, M. 2012. El Mundo con una Pluma. Croquis del Arq. Miguel Ángel Odriozola Odriozola. Montevideo: Mosca.

Guillot, M. 2018. Entrevista [03 jul. 2018]. Colonia del Sacramento - Uruguai. 2 archivos .mp3 (00:14:50, 00:55:45). Entrevista para la pesquisa de Mestrado.

Gutiérrez, R. 1989. Arquitetura latino-americana. São Paulo: Nobel.

Halbwachs, M. 2000. A memória coletiva. São Paulo: Centauro.

Intendencia de Colonia 2012. Plan de Gestión del Barrio Histórico de Colonia del Sacramento. Uruguai: Ministerio de Educación y Culturade Uruguay y Comisión del Patrimonio Cultural de la Nación. 
Le Goff, J. 1990. História e memória. Campinas, São Paulo: UNICAMP.

Lynch, K. 1960. The image of city. Cambridge: The M.I.T.

Maronna, M. 2012. Las representaciones del Uruguay turístico en 1930. Estud. perspect. tur., Ciudad Autónoma de Buenos Aires, v.21, n.3, Disponible en http://www.scielo.org.ar/scielo.php?script=sci_ arttext\&pid=S1851-17322012000300002\&lng=es\&nrm=iso (Accedido en 10/09/2018).

Pérez, L. C. 2011. Patrimonio y Arqueología en la región platense. Montevideo: Universidad de la República, Facultad de Humanidades y Ciencias de la Educación. 2011. Disponible en: https://www. colibri.udelar.edu.uy/bitstream/123456789/4482/1/FHCE_Cabrera_2011-06-15_webO.pdf (Accedido en $16 / 06 / 2017$ ).

Santos, M. 2010. Ensaios sobre a Urbanização Latino-Americana. São Paulo: Editora da Universidade de São Paulo.

Teixeira, L. E. F. 2009. Arquitetura e cidade: a modernidade (possível) em Florianópolis, Santa Catarina - 1930-1960. 377 p. Tese (Doutorado) - USP, Programa de Pós-Graduação em Arquitetura e Urbanismo, São Paulo.

Tonera\&Oliveira, R. 2015. As defesas da Ilha de Santa Catarina e do Rio Grande de São Pedro em 1786. (Disponible en: http://fortalezas.org/impressao_jpg.php?ct=fortaleza\&id_fortaleza=1\&id_ midia $=001509 \#)$

Troitiño Vinuesa, M. Á; Troitiño Torralba, L. 2016. Patrimonio Y Turismo: Reflexión Teórico Conceptual Y Una Propuesta Metodológica Integradora Aplicada Al Municipio De Carmona (Sevilla, España). Scripta Nova, Vol XX, núm. 543. ISSN: 1138-9788. (Disponible en: https://www.ucm.es/geoturis/articulos).

Troitiño Vinuesa, M. Á; Troitiño Torralba, L. 2018. Visión territorial del patrimonio y sostenibilidad del turismo. Boletín de la Asociación de Geógrafos Españoles, 78, 212-244. HTTP://dx.doi.org/10.21138/ bage. 2716

Uruguay. Administración Nacional de Puertos. 2017. Movimiento Comparativo de Pasageros: Período 2013-2017. http://www.anp.com.uy/inicio/institucional/cifras/colonia/estadisticas/terminal_fluvio_maritima/movimiento_de_pasajeros/evolucion_pasajeros/ (Consulta: 12/07/2018).

Uruguay. Ministerio del Turismo del Uruguay. 2017. Turismo Receptivo - datos del tercer Trimestre. http://mintur.gub.uy/index.php/component/jdownloads/send/4-2017/71-tercer-trimestre-2017 (Consulta: 12/01/2018).

Waisman, M. 2013: O interior da história: historiografía arquitetônica para uso de latino-americanos. São Paulo: Perspectiva.

\section{Notas}

$1 \quad$ La Isla de Santa Catarina es parte del Estado de Santa Catarina, al que se une por tres puentes de $1.200 \mathrm{mts}$ de longitud. A su vez, está rodeada de islas más pequeñas que es donde fueron construidas las fortalezas.

2 En su obra, Lynch (1960) ya menciona lo que él denomina imagen "pública” de la ciudad, que para él es la superposición de imágenes de muchos individuos. Entre los factores que influyen en la "imagen" el autor hace referencia al significado social, su función y la historia. De esta manera, si los recuerdos son resultados de procesos colectivos en un determinado contexto social, el intercambio de percepciones (como en las actividades de clase propuestas cuando los estudiantes regresan a sus comunidades) en el grupo se torna muy importante para el ejercicio de su ciudadanía y la apropriacion territorial.

3 Para la división del espacio atlántico entre Portugal y España, el 7 de junio de 1494, se firmó el Tratado de Tordesillas donde se encontraba el rayo divisor en el meridiano ubicado a 370 leguas al oeste de Cabo Verde. (BRANDÃO,2017:02).

4 Este hecho se menciona en el Plan de Gestión del Barrio Histórico de Colonia del Sacramento como uno de los motivos del reconocimiento por parte de la UNESCO como Patrimonio de la Humanidad desde 1995 (PGBHCS, 2012: 34).

Que se suspenden em 1912

6 En la isla de Santa Catarina (Brasil), el Instituto Nacional de Patrimonio Histórico Artístico (IPHAN) está preparando actualmente la incorporación de un conjunto de fortificaciones ubicadas a lo largo de la costa brasileña, entre ellas la Fortaleza de Santa Cruz de Anhatomirim y la de Santo Antônio (objetos de nuestra investigación), al Patrimonio de la Humanidad. Recientemente (en junio de 2019) se llevaron a cabo reuniones con la población, organizaciones no gubernamentales y otros agentes de las comunidades involucradas para la elaboración de Plan de Gestión de estos sitios.

7 Anotaciones de la autora durante el Seminario Internacional sobre Patrimonio y Turismo en el Mercosur, abril de 2016.

Recibido:

$24 / 07 / 2019$

Reenviado:

$31 / 07 / 2019$

Aceptado:

$26 / 10 / 2019$

Sometido a evaluación por pares anónimos 


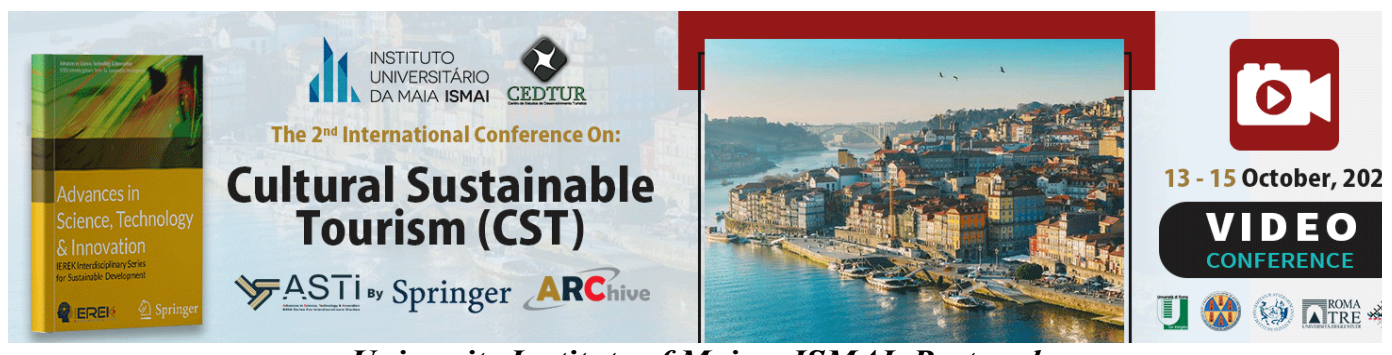

University Institute of Maia - ISMAI, Portugal

www.ismai.pt

https://www.ierek.com/events/CST2020\#introduction

Conference Email

cst@ierek-scholar.org

\section{Abstract Submissions Deadline - 15 May 2020}

This conference focuses on discussing the complex relations between culture and tourism. It also presents the methods of involving the participation of communities, in preserving, spreading, and improving the cultural heritage for the following decades. As great contributions from planners, architects, and stakeholders are exerted in order to spread the importance and role of cultural tourism and how to maintain it. This conference aims to balance between the society, environment, and tourism in order to control the negative impacts, and increase the positive ones, which can be achieved through spreading creativity, and cultural diversity, and through increasing and spreading awareness for the importance of cultural tourism. Cultural sustainable tourism (CST-2020) discusses the complex relations between culture, and tourism, and how planners, architects, and stakeholders help in conveying and spreading the importance and role of cultural tourism and how to develop it.

\section{Conference Topics}

1. Policies and Mechanisms for Heritage Preservation

1.1 Heritage Preservation and Green Economy Integration

1.2 Cultural Heritage Diversity and Green Tourism

1.3 Globalization and Heritage Management

1.4 Allocating Cultural Heritage and Environmental Resources, Wealth Conservation and Management

1.5 Heritage Preservation and Integration in Modern planning.

2. User Interaction Based Development

2.1 User Centered Design and Management for Cultural Heritage

2.2 Heritage Social Role in Sustainable Development

2.3 How Demographic Shifts Affect the Cultural Identity

2.4 Social Development in Public and Cultural Spaces

2.5 Cultural Traditions evolution through the year

3. Role of Economy in Heritage Developments

3.1 Economic Sustainability, Concepts \& Impacts

3.2 Economy and Culture, Methods for Sustainability

3.3 Achieving Sustainable Economic Development: Macroeconomic Models and

Empirical Methods

3.4 Globalization and Sustainable Economic Growth

3.5 Heritage in Socio Economic Development

4. Planning and Development of Sustainable Tourism

4.1 Building Effective Tourism Strategies

4.2 Tourism Sustainability and Economic Efficiency

4.3 New Policies and Strategies for Tourism in the Mediterranean Basin and Beyond

4.4 Integrated Relational Tourism (IRT) as a Tool of Development

4.5 Role of Authorities and Stakeholders in Effective Tourism 